\title{
Autologous Platelet-Rich Plasma Enhances the Healing of Large Cutaneous Wounds in Dogs
}

\author{
Ilaria lacopetti ${ }^{1}$, Marco Patruno ${ }^{2 *}$, Luca Melotti ${ }^{2}$, Tiziana Martinello ${ }^{3}$, Silvia Bedin ${ }^{1}$, \\ Tamara Badon ${ }^{1}$, Edoardo Maria Righetto ${ }^{4}$ and Anna Perazzi ${ }^{1 *}$
}

${ }^{1}$ Department of Animal Medicine, Production and Health, University of Padua, Padua, Italy, ${ }^{2}$ Department of Comparative Biomedicine and Food Science, University of Padua, Padua, Italy, ${ }^{3}$ Department of Veterinary Medicine, University of Bari Aldo Moro, Bari, Italy, ${ }^{4}$ Veterinary Practitioner, Padua, Italy

OPEN ACCESS

Edited by:

Roberta Perego,

University of Milan, Italy

Reviewed by:

Adolfo Maria Tambella,

University of Camerino, Italy

Dilip Kumar Garikipati,

Cleveland Clinic, United States

*Correspondence:

Anna Perazz

anna.perazzi@unipd.it

Marco Patruno

marco.pat@unipd.it

Specialty section:

This article was submitted to Comparative and Clinical Medicine,

a section of the journal

Frontiers in Veterinary Science

Received: 23 June 2020

Accepted: 22 September 2020

Published: 26 October 2020

Citation:

lacopetti I, Patruno M, Melotti L, Martinello T, Bedin S, Badon T, Righetto EM and Perazzi A (2020)

Autologous Platelet-Rich Plasma

Enhances the Healing of Large

Cutaneous Wounds in Dogs.

Front. Vet. Sci. 7:575449.

doi: 10.3389/fvets.2020.575449
Platelet-rich plasma (PRP) is known to play a crucial role in skin wound healing, in both Human and Veterinary Medicine. Remarkably, until now, no studies have reported PRP treatment in subacute full-thickness skin wounds of the dog. The aim of this study was to evaluate the effects of two consecutive applications of autologous PRP, with the second application after 15 days, in 6 dogs showing large subacute skin wounds. The percentage of contraction, re-epithelialization and healing in all treated patients indicated that no complications or side effects, associated with consecutive PRP treatments, occurred in any patient and all wounds achieved complete closure and re-epithelialization. Our results suggest a positive effect of repeated autologous topical PRP treatments in large cutaneous subacute wounds of different etiology. Therefore, this PRP treatment could represent a simple, cost-effective, and valid alternative to promote healing processes in subacute large wounds cases in dogs.

Keywords: dog, autologous platelet-rich plasma, regenerative medicine, subacute wounds, cutaneous wound healing

\section{INTRODUCTION}

Cutaneous wound healing is a physiological process that is triggered after the loss of skin integrity (1-3). This complex and dynamic response to a physical trauma comprises three overlapping phases (inflammation, proliferation and remodeling) that are initiated and orchestrated by a cascade of local responses elicited by tissue injury $(2,4-6)$. In particular, during the inflammatory phase, which reaches its peak in 2-3 days, an active role is played by platelets that release different growth factors and cytokines promoting inflammatory cells recruitment and activation. The proliferative phase involves the deposition of newly formed extracellular matrix (ECM) (collagen I fibers), epithelialization and angiogenesis stimulation reaching its climax between 2 and 3 weeks after injury. The remodeling phase, less rapid and reactive, starts between 2 and 3 weeks following injury leading to the reorganization of the collagen matrix and replacement of the granulation tissue with an acellular scar $(7,8)$. Complete wound healing depends on several parameters such as etiology of the lesion, position in the body, blood supply, defect size, tension and mobility of wound margins, susceptibility to infection and type and, in the case of large wounds, condition of the underlying tissue (9-11).

On the basis of the time in which the wound is created, cutaneous wounds can be divided into three types: (i) acute wounds, of recent formation, (ii) subacute wounds starting from about 1 week after injury, and (iii) chronic wounds if there is no healing within 6 weeks $(12,13)$. A delay of 
normal reparative processes, for different reasons, can cause subacute and chronic wounds that lead to an extension of the therapies and greater economic costs for the healing of the patients.

Platelet-rich plasma (PRP) is known to enhance wound healing and tissue regeneration, given the high number of platelets, growth factors and cytokines in it contains (9, 14, 15); this product represents a natural physiological mixture of stimulatory and inhibitory mediators that have synergistic biological effects in the wound healing environment (16). Platelets secrete several growth factors and active metabolites, and their use can have a positive influence in clinical situations requiring rapid healing and tissue regeneration considering that they are also involved in mesenchymal cell recruitment and ECM synthesis (14, 17-19). Indeed, wounds treated with PRP present an increased re-epithelialization, contraction, and neovascularization (2).

In human medicine, topical application of growth factors derived from platelets encouraged the repair of previously nonhealing wounds $(20,21)$. The beneficial therapeutic effects of PRP, with its adhesive, hemostatic and healing properties on tissue regeneration, are widely recognized in literature as an useful treatment for both cutaneous acute wounds and chronic non-healing ulcers in patients $(9,22-25)$.

Positive results have been obtained also in the veterinary field, both in acute wound experimental models (26) or in the clinical practice to treat chronic non-healing wounds. In the literature, there are various reports on the use of PRP in veterinary medicine demonstrating that it might accelerate and stimulate the healing of acute wounds and promote the repair of impaired chronic wounds as observed in dogs $(12,27-32)$, horses (1, 16, 33-36), cats $(37,38)$, sheep (39), goat (40), and pigs (41, 42). However, sometimes these results appear to be discordant, i.e., no positive effects of PRP are shown $(2,43,44)$.

The aim of the present study was to describe the wound management and the effects of the topical application of PRP, used in two consecutive applications with the second application after 15 days, in large subacute skin wounds in dogs, occurred 1-2 weeks before the first treatment.

\section{MATERIALS AND METHODS}

\section{Ethics Statement}

The study was carried out with client-owned dogs. All animal owners included in the study signed a written consent after having been notified of the relevant project information. The informed consent was discussed during the consultation and contained information about the properties of the treatment and post treatment instructions. All dogs that participated in the study were directly overseen by a veterinarian to ensure no harm was incurred during study participation.

\section{Inclusion Criteria}

The current study was conducted in the Veterinary Teaching Hospital of University of Padua and performed by the same team. To be included in the study, dogs of any breed, gender and age, had to present full-thickness skin defects from 1 to 2 weeks, in order to evaluate the wounds as subacute. The defects in different regions of thorax and abdomen were due to different etiological causes. Dogs were excluded if surgical treatment was applicable.

All dogs were selected with defects in different regions of the body and due to different etiological causes.

\section{PRP Preparation and Application Protocol}

Basic hematological and biochemical profiles were performed in all cases before PRP preparation to avoid the presence of other concomitant pathologies. Autologous PRP was prepared from peripheral venous blood with a centrifuge (Labofuge 400, Heraeus Holding, Hanau, Germany) using a double centrifugation tube method (first at 2,800 rpm for $20 \mathrm{~min}$ and then at $1,300 \mathrm{rpm}$ for $15 \mathrm{~min}$ ) described by Perazzi et al. (45). A range of $15-25 \mathrm{~mL}$ volume of blood (matched to patient weight and wound size) was collected with commercially designed platelet sequestration tubes containing sodium citrate (Vacutainer CPT; Becton, Dickinson and Company, Franklin Lakes, New Jersey, USA) and then centrifuged to obtain liquid $\mathrm{PRP}$. The final volume of PRP contained a mean $\pm \mathrm{SD}$ concentration of $1,259,50 \times 10^{3} \pm 175,50$ platelets/mL, 4- up to 6 -folds the initial platelets concentration. After a wound bed preparation, depending on the size of the different lesions, in awake patients a total of 3-6 $\mathrm{ml}$ of PRP was dropped on the wound surface including on the edge of the wound to fully cover the area of the lesion. For wounds $<50 \mathrm{~cm}^{2}$ a total volume of $3 \mathrm{ml}$ of PRP was applied, for wounds between 50 and $80 \mathrm{~cm}^{2}$ $4 \mathrm{ml}$, for wounds larger than $80 \mathrm{~cm}^{2} 6 \mathrm{ml}$. When detachment of the underlying soft tissue was present, $1 \mathrm{ml}$ of PRP was reserved and applied in the depth of the cavity. In all cases the wounds were protected by a light dry to dry covering bandage changed after 3 days the first time and subsequently weekly, after saline cleaning. Amoxicillin-clavulanic acid treatment (Synulox, Pfizer A.H., New York, USA) at a dose of $20 \mathrm{mg} / \mathrm{kg}$ twice daily per os, was administered for 7 days; no NSAID therapy nor other local treatments were administered to avoid interference with the mechanism of action of the PRP. Elizabethan collars were always applied. PRP topical application was repeated 15 days after the first treatment. The management of the second treatment was similar to the first application.

\section{Data Evaluation and Image Analyses}

Wounds were documented with photographs to measure wound area using a ruler as a reference measure. The images were captured before treatment, 3 days after the first PRP treatment, and weekly; the dimensions of the wounds, expressed in $\mathrm{cm}^{2}$, were determined using ImageJ software (Rasband, W.S., ImageJ, U. S. National Institutes of Health, Bethesda, Maryland, USA, http://imagej.nih.gov/ij/, 1997-2012), with specific plugins. The value obtained represents the average calculated from 3 repeated measurements performed for each image at the different timings to reduce the operator error. Percentage of the wound contraction, re-epithelialization and wound healing, were calculated for each wound based on the formulas already widely reported in the literature by many authors (46-49). Percentage of wound contraction $=100-\left(A_{t x} / A_{t 0} * 100\right)$. where $A$ is the area/size that has as its perimeter the margin of the initial lesion; $\mathrm{t} 0=$ 
TABLE 1 | Patient characteristics, wound size before treatment, onset time, platelet concentration, number and amount of treatment and healing time.

\begin{tabular}{|c|c|c|c|c|c|c|c|c|c|c|c|c|}
\hline Case & Breed & Sex & Age & $\begin{array}{c}\text { Weight } \\
\text { (kg) }\end{array}$ & Etiology & Body position & $\begin{array}{l}\text { Onset } \\
\text { time } \\
\text { (days) }\end{array}$ & $\begin{array}{l}\text { Initial } \\
\text { skin } \\
\text { wound } \\
\left(\mathrm{cm}^{2}\right)\end{array}$ & $\begin{array}{c}\text { Platelet } \\
\text { concentration } \\
\times 10^{3} \\
\text { platelets } / \mu \mathrm{L}\end{array}$ & $\begin{array}{l}\text { PRP } \\
\text { used } \\
1^{\circ} \\
\text { time } \\
\text { (ml) }\end{array}$ & $\begin{array}{l}\text { PRP } \\
\text { used } \\
2^{\circ} \\
\text { time } \\
\text { (ml) }\end{array}$ & $\begin{array}{c}\text { Time } \\
\text { for } \\
\text { healing } \\
\text { (days) }\end{array}$ \\
\hline 1 & $\begin{array}{l}\text { Saint } \\
\text { Bernard }\end{array}$ & $\mathrm{F}$ & $11 \mathrm{~m}$ & 42 & $\begin{array}{l}\text { Suture dehiscence } \\
\text { for Surgery } \\
\text { asportation }\end{array}$ & $\begin{array}{l}\text { Left } \\
\text { fronto-occipital } \\
\text { portion of the skull } \\
\text { up to right ear }\end{array}$ & 7 & 18,76 & 1,550 & 3 & 2 & 40 \\
\hline 2 & $\begin{array}{l}\text { Mixed } \\
\text { breed }\end{array}$ & $\mathrm{F}$ & $11 \mathrm{y}$ & 25 & $\begin{array}{l}\text { Bite by another } \\
\text { dog }\end{array}$ & $\begin{array}{l}\text { Dorso-lateral } \\
\text { region right side }\end{array}$ & 7 & 47,89 & 1,235 & $2+1$ & $1+1$ & 30 \\
\hline 3 & Bracco & $\mathrm{F}$ & $6 y$ & 30 & $\begin{array}{l}\text { Suture dehiscence } \\
\text { for hunting } \\
\text { accident }\end{array}$ & $\begin{array}{l}\text { Right thorax, } \\
\text { axillar and pectoral } \\
\text { region }\end{array}$ & 15 & 79,98 & 1,259 & 6 & 4 & 45 \\
\hline 4 & $\begin{array}{l}\text { Mixed } \\
\text { breed }\end{array}$ & M & $10 y$ & 8 & Burn lesion & Dorsal region & 15 & 91,5 & 1,050 & 6 & 4 & $\begin{array}{l}\text { Not } \\
\text { note }\end{array}$ \\
\hline 5 & Segugio & M & $8 y$ & 12 & Dog fight & $\begin{array}{l}\text { Dorsal and right } \\
\text { lateral thorax }\end{array}$ & 10 & 77,06 & 1,123 & 4 & 3 & 40 \\
\hline 6 & $\begin{array}{l}\text { Mixed } \\
\text { breed }\end{array}$ & M & $4 y$ & 15 & Dog fight & $\begin{array}{l}\text { Inguinal right } \\
\text { region }\end{array}$ & 15 & 11,32 & 1,340 & $2+1$ & $1+1$ & 30 \\
\hline
\end{tabular}

initial wound size; tx is wound size at day analyzed. Percentage of wound re-epithelialization $=A w_{t x} / A_{t x} * 100$; where $A w_{t x}$ is, the size of the area of epithelialization at the day analyzed and $A_{t x}$ is the size of the area of wound at the day analyzed. Percentage of wound healing $=100$ - percentage of non-healed area compared to the wound size at $\mathrm{T} 0=$ wound healing area; where percent of non-healed area $=$ area of granulation tissue at day $\mathrm{X} /$ initial size of wound (T0) * 100 .

\section{RESULTS}

Six dogs were enrolled in this study. Three dogs were purebred (1 Saint Bernard, 1 Bracco and 1 Segugio) and three dogs were mixed-breed. There were 3 male and 3 female. The age ranged between 11 months and 11 years. Body weight ranged between 8 and $42 \mathrm{Kg}$.

All the lesions treated had occurred for different reasons 7 to 15 days before treatment and were localized in different parts of the body (skull, thorax, dorsal and inguinal region). The treated wounds measured between 11.32 and 91.5 $\mathrm{cm}^{2}$. Patients reporting data, etiology, position, onset time, dimensions of the wounds, PRP used and time for healing are summarized in Table 1. Debridement and wound bed preparation were performed in all cases before the first treatment only; subsequently, it was not necessary for the second treatment.

Figure 1 shows the different stages of wound healing in all patients treated from the first PRP (day 0) treatment up to 30 days of follow up. Unfortunately, case 4 was missing at the final 30 day follow up visit. In all patients from the first post-treatment control ( 3 days after the application), lesions became exudative and, within 2 weeks, the amount of effusion decreased significantly. The necrotic tissue, when present, gradually disappeared and a considerable amount of granulation tissue progressively covered the bed lesion. Systemic antibiotic therapy was administered for only 7 days post treatment, and in no case there were signs of systemic infection, even where it was infected lesions as in the case 2, 5, and 6. In cases 2 and 6 , since a detachment of underlying soft tissue was present, $1 \mathrm{ml}$ of PRP was inserted deep into the cavity. No adverse reactions or side effects were observed, even in cases where PRP treatment was repeated in high doses. Wounds were considered healed when they were completely covered by the epithelium. All wounds achieved complete closure and re-epithelialization, and no complications associated with PRP treatment occurred in any patient. Healing time varied between 30 and 45 days except in case 4, where the dog missed the 30 day follow up.

No abnormal tissue formation, keloid or pathologic scarring were observed. In all cases, a hair regrowth occurred even where large losses of skin were present. Beneficial effects in large delayed healing skin wounds seem to have occurred in all treated cases. In Figure 2 are reported the percentage average of wound contraction, wound re-epithelialization and wound healing measured weekly and treated with 2 applications (at T0 and T15) compared to the wound size at T0 before first treatment.

In particular, data showed that the contraction increased quickly after the first treatment, the percentage change between T0 and T15 was 57.16\%, and after the second treatment continued to increase linearly, the percentage change between T15 and T30 was $24.28 \%$. Re-epithelialization, with respect to the contraction trend, presented an exponential growth, where the values increased in proportion to its previous value, almost doubling. In fact, the percentage change between T0 and T15 was $26.04 \%$, between T15 and T30 was 59.57\%. Considering the percentage average of healing, data showed that the first 

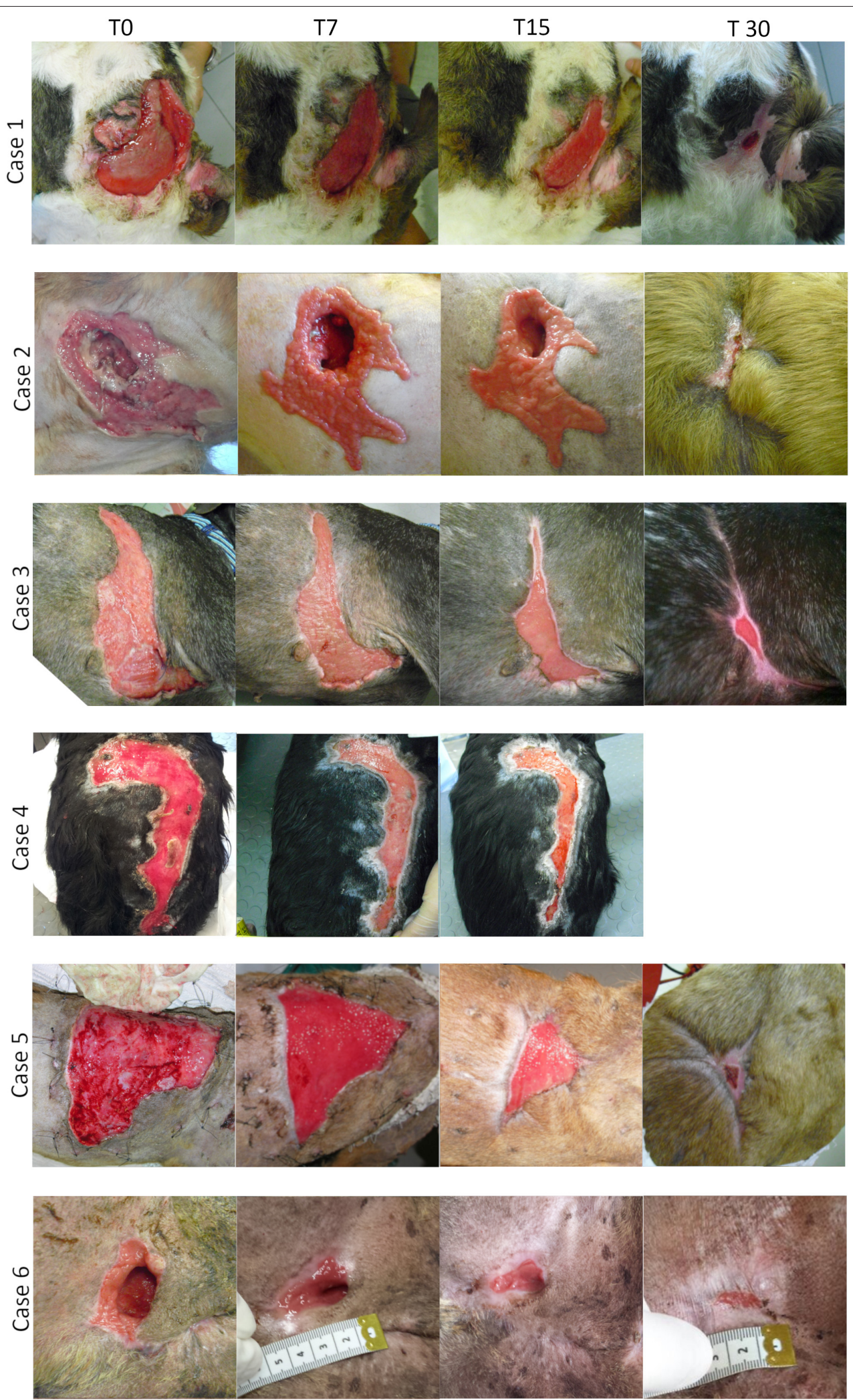

FIGURE 1 | Serial macroscopic images of the wound site of the six case at different time points (T0, T7, T15, T30). Treatments were applied after T0 e after T15. Case 4 was missing at the final 30 day follow up. 


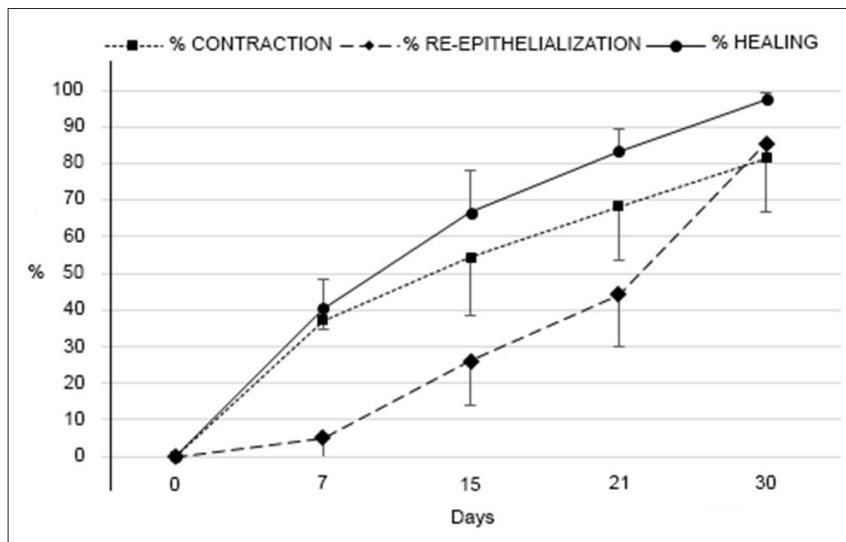

FIGURE 2 | Percent of wound contraction, wound re-epithelialization, and wound healing measured weekly.

treatment led to a percentage change (T0-T15) of $66.73 \%$, while the second treatment induced a percentage change (T15-T30) of only $30.77 \%$.

\section{DISCUSSION}

Large cutaneous wounds are an economical and physiological burden both in human and veterinary medicine because they require long healing times. Different innovative treatments have been tested during the years and, among them, PRP stands out for its beneficial characteristics. PRP is a readily available and cost-effective therapy rich in growth factors and cytokines that enhances and supports tissue regeneration by stimulating cell migration and proliferation. Its application for the treatment of skin ulcers has already been widely reported both in humans $(9,22-25)$ and animals $(1,16,29,37,39,42)$. However, studies regarding the clinical efficacy of PRP in dogs for skin wound healing are rare. Particularly, in experimental acute full-thickness wounds trial, different studies reported a positive outcome with a better quality of the newly regenerated skin respect than the control group after a single administration of locally injected autologous PRP treatment $(28,32)$ and in sub-dermal plexus skin flap (50). Moreover, beneficial effects are also reported after repeated injections as three (30) or four times (31).

In contrast others have shown that the topical application of PRP in canine medicine for skin wound healing did not lead to any amelioration of the healing process compared to control groups or other treatments $(2,43,44)$. These discrepancies might be due to variables between experiments such us experimental wound model, PRP biology, preparation techniques and differences in treatments protocol or time-points investigation (43).

Only few clinical papers report treatments in chronic or nonhealing skin wounds in dogs; furthermore every study reported PRP treatments with a single topic application (12, 27, 29). Tambella et al. (12) described topical application of autologous platelet gel (PLG) to treat chronic decubital ulcers in 18 dogs showing more rapid healing in lesion treated with PLG compared to control wounds. In the other two reports, the beneficial effects with improvement in the management of chronic delayed wound healing were described in a single clinical case $(27,29)$. Finally, there are no reports in the literature describing the treatment of subacute skin lesions using PRP in dog.

This is the first report describing a two consecutive topical application of autologous PRP for the treatment of large subacute skin wounds on a series of dogs. Six dogs presenting a subacute large skin wound (wound area, mean \pm SD $54.42 \pm 13.8 \mathrm{~cm}^{2}$ ), which occurred between 1 and 2 weeks before enrolment, were included in the present study. All wounds, of different size, etiology and position in the body, were treated with a topical application of autologous PRP and it was repeated after 2 weeks. The decision to apply PRP after 2 weeks after the first treatment was based on the fact that the biological half-life of the platelets in dogs, as in human, is about 10 days; this way wound healing was stimulated for a second time after the physiological platelet apoptosis $(51,52)$. The second application of topical autologous PRP seems to highlight an improvement in contraction and re-epithelialization in all wounds. Particularly, a faster wound contraction rate was observed during the 15 days after the first treatment and showed a continuing increase following the second treatment. In contrast, re-epithelialization showed better improvement after the second treatment. These clinical data could indicate that repeat the PRP application after 15 days can be useful for both contraction and re-epithelialisation of the wound by supporting their clinical use also in subacute skin wounds as well as observed in experimental studies for acute skin wound healing in dogs $(30,31)$.

All wounds healed completely between 45 days after the first PRP treatment and no abnormal tissue formation, keloid or pathologic scarring was observed after this protocol of PRP treatment similar to that reported also by Tambella at al. (12). Moreover, a full hair regrowth was observed in all patients as reported also in the literature $(27,29)$. In all cases, cleaning was only carrier out before first PRP application. Antibiotics were administered for only 1 week after the first treatment but no evidences of wound infection were observed until complete healing in all patients. This might be due to the antibacterial properties of PRP that have may contributed to the prevention of infection $(19,31)$. NSAID were not administered after PRP treatments because they could interfere with platelets activation and aggregation, thus impairing its beneficial effects on wound healing (53-57). After PRP treatments, all lesion were covered by a light bandage, these bandages were changed first after about 3 days to verify the wound conditions then later weekly. This decision was made to avoid removing the newly formed tissue by changing the bandage. No tissue damage was observed upon dressing removal using abundant saline solution; similar data are reported by Tambella et al. (12).

To the Authors knowledge there are no published data describing the effect of two consecutive applications, with the second application after 15 days, in large subacute skin lesions in dog. Moreover, no repeated PRP protocols are reported in the canine medical field. Despite the observed beneficial effects and considering that it is the only study performed on subacute lesions the comparison of our data with other studies reported in 
the literature is challenging since the lack of control lesions and the different initial dimensions of the lesions.

The limitations of the present case series study include the low number of sample, the heterogeneity of the wounds types and the absence of control wounds, since the clinical nature of the study. Further studies using a larger number of animals (eventually experimental animals) are required to validate the results obtained and to point out a clear mechanism of action.

In conclusion, our results suggest that a topical application of autologous PRP, repeated once with a time gap of 2 weeks, may represent a simple, safe and cost-effective therapy for subacute skin wounds in dogs. No complications associated with our protocol of PRP treatment occurred in any patient and all wounds achieved complete closure and epithelialization. The PRP could be useful to enhance wound repair representing a valid alternative therapy to promote cutaneous wound healing in subacute large skin wounds when traditional surgery cannot be performed for different reasons.

\section{DATA AVAILABILITY STATEMENT}

The raw data supporting the conclusions of this article will be made available by the authors, without undue reservation.

\section{ETHICS STATEMENT}

Ethical review and approval was not required for the animal study because the current clinical study was carried out with clientowned dogs. All animal owners included in the study signed a

\section{REFERENCES}

1. DeRossi R, Coelho ACAO, De Mello GS, Frazílio FO, Leal CRB, Facco GG, et al. Effects of platelet-rich plasma gel on skin healing in surgical wound in horses. Acta Cir Bras. (2009) 24:276-81. doi: 10.1590/S0102-86502009000400006

2. Sardari K, Emami MR, Kazemi H, Movasagi AR, Goli AA, Lotfi A, et al. Effects of platelet-rich plasma (PRP) on cutaneous regeneration and wound healing in dogs treated with dexamethasone. Comp Clin Path. (2010) 20:155-62. doi: 10.1007/s00580-010-0 972-y

3. Knox RL, Hunt AR, Collins JC, DeSmet M, Barnes S. Platelet-rich plasma combined with skin substitute for chronic wound healing: a case report. $J$ Extra Corpor Technol. (2006) 38:260-4.

4. Dart AJ, Dowling BA, Smith CL. Topical treatments in equine wound management. Vet Clin Equine. (2005) 21:7789. doi: 10.1016/j.cveq.2004.11.003

5. Theoret CL. The pathophysiology of wound repair. Vet Clin North Am Equine Pract. (2005) 21:1-13. doi: 10.1016/j.cveq.2004.11.001

6. Ficarelli E, Bernuzzi G, Tognetti E, Bussolati O, Zucchi A, Adorni D, et al. Treatment of chronic venous leg ulcers by platelet gel. Dermatol Ther. (2008) 21(Suppl. 1):13-7. doi: 10.1111/j.1529-8019.2008.00196.x

7. Cerqueira MT, Pirraco RP, Marques AP. Stem cells in skin wound healing: are we there yet? Adv Wound Care. (2015) 5:164-75. doi: 10.1089/wound.2014.0607

8. Watson T. Soft Tissue Repair and Healing Review. Electrotherapy Today (2016). p. 16. Available online at: http://www.electrotherapy.org/modality/ soft-tissue-repair-and-healing-review written consent after having been notified of the relevant project information. The informed consent was discussed during the consultation and contained information about the properties of the treatment and post treatment instructions. All dogs that participated in the study were directly overseen by a veterinarian to ensure no harm was incurred during study participation. An ethical review process by the Animal Welfare Committee of the University of Padua was not required for our study. PRP's safety has been established for over 20 years for its wound healing properties and it's proven effectiveness has extended across multiple medical specialties both in Human and Veterinary Medicine, including orthopedics, sports medicine, dental and maxillofacial surgery dermatology (chronic wound healing), and ophthalmology, cosmetic surgery. PRP is safe, tested and effective because it is autologous enriched plasma. Written informed consent was obtained from the owners for the participation of their animals in this study.

\section{AUTHOR CONTRIBUTIONS}

ER, TM, and LM: acquisition of data and analysis and interpretation of data. AP and II: contributions to conception and design and acquisition of clinical data. SB and TB: contributions to laboratory test. II and MP: drafting the manuscript and revising. All authors read and approved the final manuscript.

\section{FUNDING}

This work was supported by grants from the University of Padova, Italy (BIRD: 183588/18).
9. Crovetti G, Martinelli G, Issi M, Barone M, Guizzardi M, Campanati B, et al. Platelet gel for healing cutaneous chronic wounds. Transfus Apher Sci. (2004) 30:145-51. doi: 10.1016/j.transci.2004.01.004

10. Maciel FB, Derossi R, Módolo TJC, Pagliosa RC, Leal CRJ, Delben AAST. Scanning electron microscopy and microbiological evaluation of equine burn wound repair after platelet-rich plasma gel treatment. Burns. (2012) 38:105865. doi: 10.1016/j.burns.2012.02.029

11. Prades M. Current trends in regenerative medicine for soft tissue musculoskeletal injury. In: Proceedings of the Southern European Veterinary Conference Congreso Nacional AVEPA. Barcelona (2007).

12. Tambella AM, Attili AR, Dini F, Palumbo Piccionello A, Vullo C, Serri E, et al. Autologous platelet gel to treat chronic decubital ulcers: a randomized, blind controlled clinical trial in dogs. Vet Surg. (2014) 43:72633. doi: 10.1111/j.1532-950X.2014.12148.x

13. ArneŽ ZM, Papa G, Ramella V, Andrea F, Stocco C. Treatment of subacute traumatic lower limb wounds by assisted healing and delayed selective reconstruction. Plast Thor Surg Orth Ophth. (2018) 11:17786. doi: 10.1007/15695_2018_124

14. Bennett NT, Schultz GS. Growth factors and wound healing: part II. Role in normal and chronic wound healing. Am J Surg. (1993) 166:7481. doi: 10.1016/S0002-9610(05)80589-6

15. Knighton DR, Ciresi KF, Fiegel VD, Austin LL, Butler EL. Classification and treatment of chronic nonhealing wounds: successful treatment with autologous platelet-derived wound healing factors (PDWHF). Ann Surg. (1986) 204:322-30. doi: 10.1097/00000658-198609000-00011

16. Monteiro SO, Lepage OM, Theoret CL. Effects of platelet-rich plasma on the repair of wounds on the distal aspect of the forelimb in horses. Am J Vet Res. (2009) 70:277-82. doi: 10.2460/ajvr.70.2.277 
17. Anitua E, Sánchez M, Orive G, Andía I. The potential impact of the preparation rich in growth factors (PRGF) in different medical fields. Biomaterials. (2007) 28:4551-60. doi: 10.1016/j.biomaterials.2007.06.037

18. Borzini P, Mazzucco L. Tissue regeneration and in loco administration of platelet derivatives: clinical outcome, heterogeneous products, and heterogeneity of the effector mechanisms. Transfusion. (2005) 45:1759-67. doi: 10.1111/j.1537-2995.2005.00 600.x

19. Yuan T, Zhang CQ, Tang MJ, Guo SC, Zeng BF. Autologous plateletrich plasma enhances healing of chronic wounds. Wounds. (2009) 21:2805. doi: 10.1002/14651858.CD006899.pub3

20. Lacci KM, Dardik A. Platelet-rich plasma: support for its use in wound healing. Yale J Biol Med. (2010) 83:1-9.

21. Yang HS, Shin J, Bhang SH, Shin JY, Park J, Im G, et al. Enhanced skin wound healing by a sustained release of growth factors contained in plateletrich plasma. Exp Mol Med. (2011) 43:622-9. doi: 10.3858/emm.2011.43.1 1.070

22. Ahmed M, Reffat SA, Hassan A, Eskander F. Platelet-rich plasma for the treatment of clean diabetic foot ulcers. Ann Vasc Surg. (2017) 38:20611. doi: 10.1016/j.avsg.2016.04.023

23. Motolese A, Vignati F, Antelmi A, Saturni V. Effectiveness of platelet-rich plasma in healing necrobiosis lipoidica diabeticorum ulcers. Clin Exp Dermatol. (2015) 40:39-41. doi: 10.1111/ced.1 2474

24. O'Connell SM, Impeduglia $\mathrm{T}$, Hessler $\mathrm{K}$, Wang XJ, Carroll RJ, Dardik H. Autologous platelet-rich fibrin matrix as cell therapy in the healing of chronic lower-extremity ulcers. Wound Repair Regen. (2008) 16:749-56. doi: 10.1111/j.1524-475X.2008.00 426.x

25. Suthar M, Gupta S, Bukhari S, Ponemone V. Treatment of chronic nonhealing ulcers using autologous platelet rich plasma: a case series. J Biomed Sci. (2017) 24:1-10. doi: 10.1186/s12929-017-0324-1

26. Tambella AM, Attili AR, Dupré G, Cantalamessa A, Martin S, Cuteri V, et al. Platelet-rich plasma to treat experimentally-induced skin wounds in animals: a systematic review and meta-analysis. PLoS ONE. (2018) 13:e0191093. doi: 10.1371/journal.pone.019 1093

27. Kim JH, Park C, Park HM. Curative effect of autologous platelet-rich plasma on a large cutaneous lesion in a dog. Vet Dermatol. (2009) 20:1236. doi: 10.1111/j.1365-3164.2008.00711.x

28. Karayannopoulou M, Psalla D, Kazakos G, Loukopoulos P, Giannakas N, Savvas I, et al. Effect of locally injected autologous platelet-rich plasma on second intention wound healing of acute full-thickness skin defects in dogs. Vet Comp Orthop Traumatol. (2015) 28:172-8. doi: 10.3415/VCOT-14-060088

29. Chung TH, Baek DS, Kim N, Park JH, Park C. Topical allogeneic platelet-rich plasma treatment for a massive cutaneous lesion induced by disseminated intravascular coagulation in a toy breed dog. Ir Vet J. (2015) 68:1-4. doi: 10.1186/s13620-015-0 032-7

30. Jee CH, Eom NY, Jang HM, Jung HW, Choi ES, Won JH, et al. Effect of autologous platelet-rich plasma application on cutaneous wound healing in dogs. J Vet Sci. (2016) 17:79-87. doi: 10.4142/jvs.2016.17.1.79

31. Farghali HA, AbdElKader NA, Khattab MS, AbuBakr HO. Evaluation of subcutaneous infiltration of autologous platelet-rich plasma on skin-wound healing in dogs. Biosci Rep. (2017) 37:BSR20160503. doi: 10.1042/BSR2016 0503

32. Hussein SM. Effects of autologous platelet-rich plasma on skin healing in dogs. Ir J Vet Sci. (2018) 32:275-83. doi: 10.33899/ijvs.2019.153864

33. Iacono E, Merlo B, Pirrone A, Antonelli C, Brunori L, Romagnoli N, et al. Effects of mesenchymal stem cells isolated from amniotic fluid and platelet-rich plasma gel on severe decubitus ulcers in a septic neonatal foal. Res Vet Sci. (2012) 93:1439-40. doi: 10.1016/j.rvsc.2012.0 4.008

34. Carter CA, Jolly DG, Worden CE, Hendren DG, Kane CJM. Platelet-rich plasma gel promotes differentiation and regeneration during equine wound healing. Exp Mol Pathol. (2003) 74:244-55. doi: 10.1016/S0014-4800(03)00 017-0
35. Iacopetti I, Perazzi A, Ferrari V, Busetto R. Application of platelet-rich gel to enhance wound healing in the horse: a case report. J Equine Vet Sci. (2012) 32:123-8. doi: 10.1016/j.jevs.2011.08.012

36. Pereira RC da F, De La Côrte FD, Brass KE, da Silva Azevedo M, Gallio M, Cantarelli C, et al. Evaluation of three methods of platelet-rich plasma for treatment of equine distal limb skin wounds. J Equine Vet Sci. (2019) 72:1-7. doi: 10.1016/j.jevs.2017.10.009

37. Gemignani F, Perazzi A, Iacopetti I. Use of canine sourced platelet-rich plasma in a feline contaminated cutaneous wound. Can Vet J. (2017) 50:1191-4.

38. Ferrari JT, Schwartz P. Prospective evaluation of feline sourced plateletrich plasma using centrifuge-based systems. Front Vet Sci. (2020) 12:322. doi: $10.3389 /$ fvets.2020.00322

39. Badis D, Omar B. The effectiveness of platelet-rich plasma on the skin wound healing process: A comparative experimental study in sheep. Vet World. (2018) 11:800-8. doi: 10.14202/vetworld.2018.800-808

40. AL-Bayati AH, Al-Asadi RN, Mahdi AK, Al-Falahi NH. Effects of autologous platelets rich plasma on full-thickness cutaneous wounds healing in goats. Int J Anim Vet Adv. (2013) 5:233-9. doi: 10.19026/ijava.5. 5603

41. Blanton MW, Hadad I, Johnstone BH, Mund JA, Rogers PI, Eppley $\mathrm{BL}$, et al. Adipose stromal cells and platelet-rich plasma therapies synergistically increase revascularization during wound healing. Plast Reconstr Surg. (2009) 123(Suppl. 2):56-64. doi: 10.1097/PRS.0b013e31819 1be2d

42. Tsai HC, Chang GRL, Fan HC, Ou-Yang H, Huang LC, Wu SC, et al. A mini-pig model for evaluating the efficacy of autologous platelet patches on induced acute full thickness wound healing. BMC Vet Res. (2019) 15:1-13. doi: 10.1186/s12917-019-1 932-7

43. Mehrjerdi HK, Sardari K, Emami MR, Movassaghi AR, Goli AA, Lotfi A, et al. Efficacy of autologous platelet-rich plasma (PRP) activated by thromboplastin-d on the repair and regeneration of wounds in dogs. Iran J Vet Surg. (2008) 3:19-30.

44. Hermeto LC, Rossi R de, Pádua SB de, Pontes ERJ, Santana AE. Comparative study between fibrin glue and platelet rich plasma in dogs skin grafts. Acta Cir Bras. (2012) 27:789-94. doi: 10.1590/S0102-8650201200110 0008

45. Perazzi A, Busetto R, Martinello T, Drigo M, Pasotto D, Cian F, et al. Description of a double centrifugation tube method for concentrating canine platelets. BMC Vet Res. (2013) 9:146. doi: 10.1186/1746-6148-9-146

46. Kaufman T, Levin M, Hurwitz DJ. The effect of topical hyperalimentation on wound healing rate and granulation tissue formation of experimental deep second degree burns in guinea-pigs. Burns Incl Therm Inj. (1984) 10:2526. doi: 10.1016/0305-4179(84)90003-2

47. Sardari K, Kakhki EG, Mohri M. Evaluation of wound contraction and epithelialization after subcutaneous administration of Theranekron $\AA$ in cows. Comp Clin Path. (2007) 16:197-200. doi: 10.1007/s00580-006-0 $657-8$

48. Xu R, Xia H, He W, Li Z, Zhao J, Liu B, et al. Controlled water vapor transmission rate promotes wound-healing via wound re-epithelialization and contraction enhancement. Sci Rep. (2016) 18:1-12. doi: 10.1038/srep24596

49. Xu GM, Shi XM, Cai JF, Chen S Le, Li P, Yao CW, et al. Dual effects of atmospheric pressure plasma jet on skin wound healing of mice. Wound Repair Regen. (2015) 23:878-84. doi: 10.1111/wrr.12364

50. Karayannopoulou M, Papazoglou LG, Loukopoulos P, Kazakos G, Chantes A, Giannakas $\mathrm{K}$, et al. Locally injected autologous platelet-rich plasma enhanced tissue perfusion and improved survival of long subdermal plexus skin flaps in dogs. Vet Comp Orthop Traumatol. (2014) 27:37986. doi: 10.3415/VCOT-14-02-0030

51. Mason KD, Carpinelli MR, Fletcher JI, Collinge JE, Hilton AA, Ellis S, et al. Programmed anuclear cell death delimits platelet life span. Cell. (2007) 128:1173-86. doi: 10.1016/j.cell.2007.01.037

52. Sjaastad V, Sand O, Hove K. Physiology of Domestic Animals. 3nd ed. Oslo: Scandinavian Veterinary Press (2016).

53. Anderson K, Hamm RL. Factors that impair wound healing. J Am Coll Clin Wound Spec. (2012) 4:84-91. doi: 10.1016/j.jccw.2014.03.001

54. Brainard BM, Meredith CP, Callan MB, Budsberg SC, Shofer FS, Driessen $B$, et al. Changes in platelet function, hemostasis, \& PG expression after 
treatment w/ NSAIDs w/ various COX selectivities in dogs. Am J Vet Res. (2007) 68:251-7. doi: 10.2460/ajvr.68.3.251

55. Busti AJ, Hooper JS, Amaya CJ, Kazi S. Effects of perioperative antiinflammatory and immunomodulating therapy on surgical wound healing. Pharmacotherapy. (2005) 25:156691. doi: 10.1592/phco.2005.25.11.1566

56. Fairweather M, Heit YI, Buie J, Rosenberg LM, Briggs A, Orgill DP, et al. Celecoxib inhibits early cutaneous wound healing. J Surg Res. (2015) 194:71724. doi: $10.1016 /$ j.jss.2014.12.026

57. Schafer AI. Effects of nonsteroidal anti-inflammatory therapy on platelets. Am J Med. (1999) 106:25S-36S. doi: 10.1016/S0002-9343(99)00114-X
Conflict of Interest: The authors declare that the research was conducted in the absence of any commercial or financial relationships that could be construed as a potential conflict of interest.

Copyright (c) 2020 Iacopetti, Patruno, Melotti, Martinello, Bedin, Badon, Righetto and Perazzi. This is an open-access article distributed under the terms of the Creative Commons Attribution License (CC BY). The use, distribution or reproduction in other forums is permitted, provided the original author(s) and the copyright owner(s) are credited and that the original publication in this journal is cited, in accordance with accepted academic practice. No use, distribution or reproduction is permitted which does not comply with these terms. 